\title{
MEASURING GROWTH CONDITIONS OF SALAD PLANTS USING SENSORS: A HIGH SCHOOL PROJECT
}

\author{
L. Thapa $^{1, *}$, H. Naseer ${ }^{1}$, S. El-kaiy ${ }^{1}$, T. Bartoschek ${ }^{1}$ \\ ${ }^{1}$ Institute for Geoinformatics, University of Munster - (1_thap01, h_nase01, s_elka01, bartoschek)@ uni-muenster.de
}

Commission V, SS: Student Session

KEY WORDS: Geoinformatics, High School Students, Agriculture, Sensors, Growth Conditions

\begin{abstract}
:
Geoinformatics (GI) education is widely used as a spatial visualization-interdisciplinary tools for its ability to understand the geographical phenomenon around us in the past and model the future scenario. Its global importance and usage have made the need of disseminating the education with public and school students. The MSc. Students of different backgrounds at Institute for Geoinformatics in the University of Munster were involved in one of such works through the seminar cum project on 'Transdisciplinary education in Geoinformatics' through GI@School Lab with the aim of engaging high school students on applying GI knowledge on Agriculture. The grade 12 students were presented with the ongoing GI empowered research projects at first such that the school students developed the project ideas of their interests to use GI on agricultural sectors based on which MSc students developed 4 different projects and Growth Condition (Sensors) is one of them. This project aims to determine the best suited condition for Salad plants growth based on the size of the Salad leaves measured after monitoring the growth of the plants by planting them on 4 plastic boxes filled with same soil type but in different lighting conditions and water conditions to be measured by the concerned sensors to after the 8 weeks of indoor growth. The project execution week took place as the 5-day workshop and feedbacks were taken as questionnaire surveys from the participated students and concerned teachers for the project evaluation. The sensors-collected data could even serve as the ground truth data of a citizen observatory projects for Copernicus in-situ component. The whole project aims at reducing generational gaps between the students by bringing them the opportunity for knowledge cocreation through transdisciplinary projects on agricultural sector using GI technologies.
\end{abstract}

\section{INTRODUCTION}

\subsection{General Background}

Geoinformatics, with its everyday applications in navigation for commutation to modelling complex spatio-temporal behaviour of natural phenomenon, has been emerging as a ubiquitous spatial visualization-interdisciplinary tools to support decision making. Disseminating geoinformatics (GI) knowledge to the school students not only form the foundation of GI Science but also make them familiar with the technological aspects of addressing global earth challenges like climate change, global warming, food security. Besides, the high school education may not be able to incorporate everyday advancing Science, Technology, Engineering, Mathematics (STEM) knowledge in its syllabus. So, collaborating with the K-12 School for this type of project can bridge gaps between the school students and current scientific developments by transferring knowledge and research from the University labs. Also, linking school students and graduate students through such transdisciplinary projects provide the platform for knowledge co-creation and can reduce transgenerational communication gaps in education.

\subsection{Project Introduction}

The GI@School Lab, started as a student driven initiative of IFGI in 2006 has been continuously working on GI Science research and development activities by collaborating with high- school students and teachers (K-12) as its main target groups. The students are involved in courses and project weeks that lead to the development of products such as educational resources, software, mobile apps, web-portals and hardware, while the teachers are included in trainings to include GI Science and GI Systems in the regular subjects. This project resembles one of the similar activities that is being carried out in cooperation with teachers and high-school students from Anne-FrankGesamtschule located in Havixbeck, Germany. The specific theme has been set every year for each of the projects since 2008; theme for this year is agriculture and its future. So, all the activities carried out this year through the project aim to study the past of agriculture; to understand the present scenario; to ponder how the future scenario can be by sing GI science concepts, technology and tools through the engagement of the Grade 12 student from Havixbeck and MSc students from IFGI.

The project was executed in two parts: first, the seminar that involved the visit of 78 high school students to the Institute for Geoinformatics (IFGI) at University of Muenster. They were presented with the ongoing GI empowered research at the Institute based on which school students presented 8 different group ideas that can be applied in the agricultural sectors through the posters. Then MSc. Students at IFGI taking the course "Transdisciplinary Education in Geoinformatics" developed 4 group projects namely historical data (climate, satellite), counting insects, growth conditions (sensors) and agricultural vehicle/robot by addressing their ideas from presentations; one additional group was created as a media

\footnotetext{
* Corresponding author
} 
group to create the video product of the project. The further work involved the interaction with school students by presenting them the printed poster versions of projects during the school visit and asking their comments on each of the projects. With all the suggestions incorporated, preparations were carried out by the MSc Students to teach the school students on how to do their respective projects. The second part involved 5-day workshop on September 17-21, 2018 to execute the project ideas into reality by integrating Msc. Students and 71 students from the school for knowledge sharing and cocreation. The final outcome of whole project involved ArcGIS Online story maps showing the vegetation changes on historical satellite images and drone images on Google Earth Engine code editor by computing Normalized Difference Vegetation Index (NDVI), identification of different insects species, their locations and insects hotels creation, fully autonomous-driving robot that can be tracked and is able to collect geodata for automatic upload in open sense map, best temperature-water condition for Salad plants by teaching the school students the theoretical and practical knowledge associated with geospatial technologies involving both the image analysis, sensor technology, programming and entomology with the learning by doing approach under the direct supervision of MSc students.

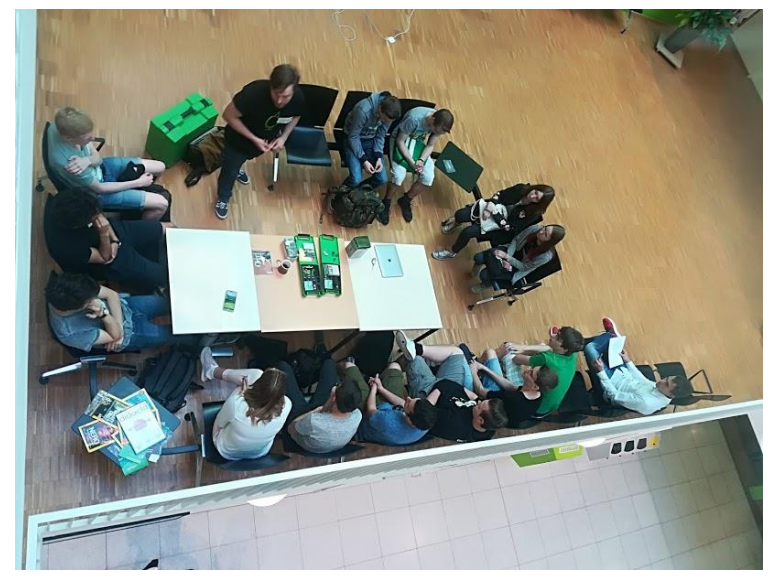

a.

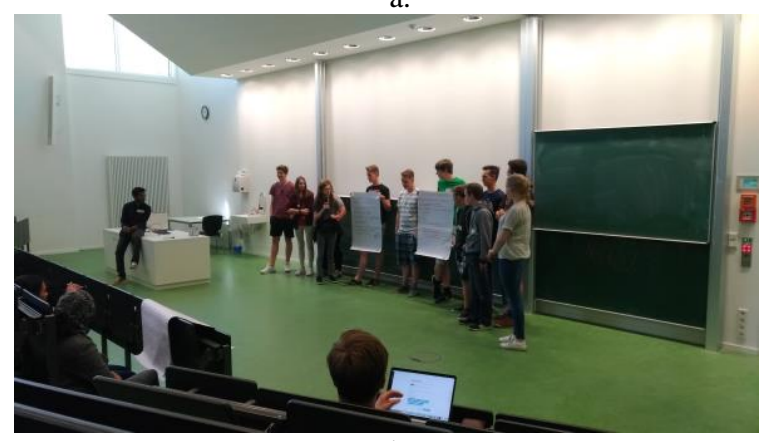

b.

Figure 1: a. presenting ongoing research about senseBox in IFGI, b. school students presenting their project ideas

\subsection{Context on Growth Condition (Sensor) Project}

Geoinformatics has ample of applications, and offers many GItools in understanding the various aspects of agriculture, analysing its data and suggesting the necessary measures for future enhancement. Agriculture is one of the most important profession around the globe that is directly related with food security. The food we eat is grown through different plants, the plants are nurtured and supplied to us through various agricultural activity. Monitoring plant growth and ensuring the best condition for its growth is very essential for high yield. Also, climate change with variations in temperature and rains/drought are disturbing the natural growth of plants. So, creating an artificial environment with best suited temperature and watering condition can help to combat with the changing climate and its influence on the plant's growth and production.

This project aims to use different sensors to monitor the growth of Salad plants to be planted in 4 plastic boxes with different temperature, amount of water supply and LED light conditions for 8 weeks of observation. The final result will be the identification of suitable condition of Salad plant growth to be measured by the length of leaves of these plants.

\section{PROJECT EXECUUTION}

\subsection{Organization and Task Division}

The project week started on Monday, September 17th 2018 at 08:30 am in the lecture hall of the Geo 1 building at the University of Münster; brief introduction about the project was given to all the participants including students, teachers, professors and invited subject experts and lasted till September $21^{\text {st }}, 2018.18$ students interested in this project were mentored by 2 of the Master students and a SenseBox expert from GI@School Lab and, following activities were carried out during the 5 days' workshop:

\begin{tabular}{|c|c|c|c|}
\hline Day & Location & Activity & Participants \\
\hline Monday & IFGI & Developing & 18 students \\
\hline & & $\begin{array}{l}\text { background on } \\
\text { SenseBox, } \\
\text { Sensors } \\
\text { Arduino }\end{array}$ & $\begin{array}{l}\text { divided in the } \\
\text { group of } 6 \\
\text { students; } \\
\text { Supervisor } \\
\text { (MSc students) } \\
\text { from IFGI }\end{array}$ \\
\hline Tuesday & $\begin{array}{l}\text { Havixbeck } \\
\text { School }\end{array}$ & $\begin{array}{l}\text { Environmental } \\
\text { Setting (Finding } \\
\text { physical location } \\
\text { for plastic boxes, } \\
\text { setting with } \\
\text { soils/Watering } \\
\begin{array}{l}\text { System, Power } \\
\text { Supply, Digital } \\
\text { clock) }\end{array}\end{array}$ & $\begin{array}{l}18 \text { students } \\
\text { divided in the } \\
\text { group of } 6 \\
\text { students; } 2 \\
\text { Supervisor } \\
\text { (MSc students) } \\
\text { from IFGI }\end{array}$ \\
\hline Wednesday & $\begin{array}{l}\text { Havixbeck } \\
\text { School }\end{array}$ & $\begin{array}{l}\text { Building data } \\
\text { loggers, Placing } \\
\text { Sensors/planting } \\
\text { Salad } \\
\text { seeds/Instructions } \\
\text { on growth } \\
\text { conditions }\end{array}$ & $\begin{array}{l}18 \text { students } \\
\text { divided in the } \\
\text { group of } 6 \\
\text { students; } 2 \\
\text { Supervisor } \\
\text { (MSc students) } \\
\text { from IFGI }\end{array}$ \\
\hline Thursday & $\begin{array}{l}\text { Havixbeck } \\
\text { School }\end{array}$ & $\begin{array}{l}\text { Possible ways of } \\
\text { observing } \\
\text { collected data, }\end{array}$ & $\begin{array}{l}18 \text { students } \\
\text { divided in the } \\
\text { group of } 6\end{array}$ \\
\hline
\end{tabular}




\begin{tabular}{|l|l|l|l|}
\hline | & $\begin{array}{l}\text { analysis on } \\
\text { collected dummy } \\
\text { data, instructions } \\
\text { on monitoring } \\
\text { the growth, } \\
\text { preparing } \\
\text { presentation } \\
\text { content. }\end{array}$ & $\begin{array}{l}\text { Supervisor } \\
\text { (MSc students) } \\
\text { from IFGI }\end{array}$ \\
Friday & School & $\begin{array}{l}\text { Final } \\
\text { Presentation }\end{array}$ & $\begin{array}{l}\text { Sepresentatives } \\
\text { of the project. }\end{array}$ \\
\hline
\end{tabular}

Table 2: Daily Activity schedule during project week

With the theoretical background on sensors, their importance, practical exercises on Arduino on blockly carried out on University, rest of the work: setting up the environment of Salad plants growth, fitting the sensors through the senseBox and starting the measurement were carried out in the school.

\subsection{Tools and Methods used}

The project uses senseBox, one of the products of GI@School developed as a Citizen Science Toolkit for home and schools. The senseBox is a do-it-yourself kit for stationary and mobile sensor stations, following the concepts of open science that allows setting sensors stations for measuring environmental data on climate, air quality, traffic, noise and others in a locationspecific way. It promotes digital education and is usable as a class box that consists of an Arduino Uno microcontroller, circuits components, different sensors and data storage device [1].

The sensors used in the project includes waterproof digital temperature and soil moisture sensor fitted externally by connecting with senseBox, air temperature and visible light sensors already built -in with the senseBox were used.

The senseBox supports Arduino programming for automatically measuring the data from sensors. The students were taught how to program in Arduino and use blockly, the online platform having the blocks of in-built codes that is able to generate the Arduino codes at IFGI building in the University. Though blockly was easy to learn, students learnt and coded with Arduino because of internet problems. Also, the theoretical background on sensors, their importance in agriculture monitoring were taught to students. Students were engaged in the whole 5 days with the activities mentioned in the Table 2 .

Four plastic boxes filled with soil were kept inside the school to create indoor environments; the waterproof temperature measuring sensor for measuring soil temperature, soil moisture sensor for measuring the water content supplied and visible light sensors are fitted to each of the boxes along with the LED bulbs (Figure 2). The Salad seeds were planted on each of those boxes. Different criteria were set in all four boxes; low light and low water, low light and high water, high light and low water, high light and high water. To control the lighting system, two bulbs have been fitted such that the high light includes the lighting of both the bulbs and low light includes the lighting of only one bulb; also, two different water amounts have been set for the low and high-water conditions. All the plastic boxes are enclosed by the external black plastic garbage bags to avoid the interference of external environment. Besides, air temperature

sensor and humidity sensor from the SenseBox are also kept outside the boxes to measure the outside air conditions to see if it has any impact on the growth of salad plants enclosed in the boxes. Two students, on a rotational basis to make sure all will participate, have been assigned for pouring the water 3 times a week, Monday, Wednesday and Friday on the plants.

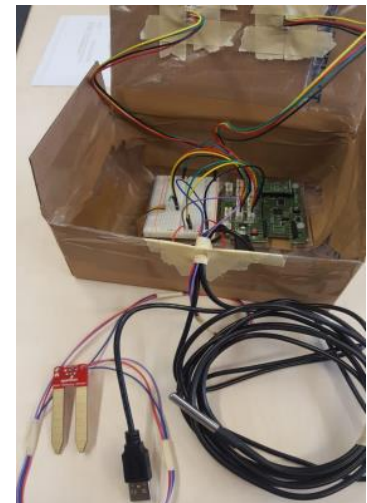

a.

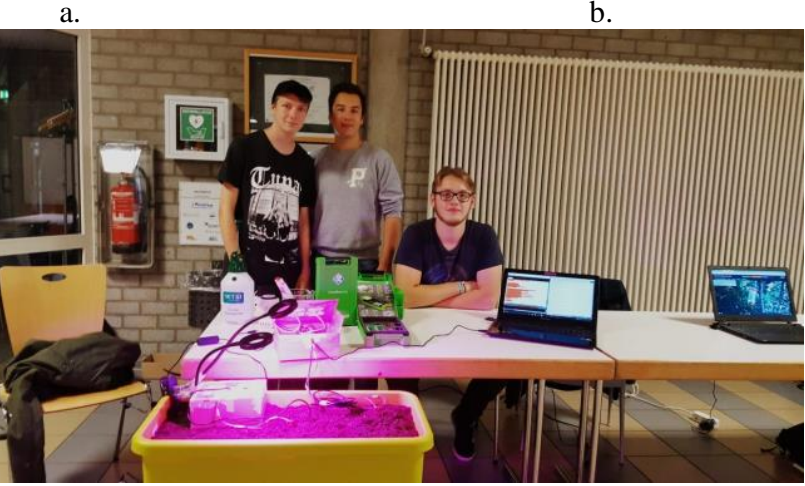

Figure 3: a. sensors to be put inside the plastic box field and their connection for senseBox, b. plastic box simulated as salad plants field filled with soil and necessary sensors connection, c. environmental setup for salad plant growth

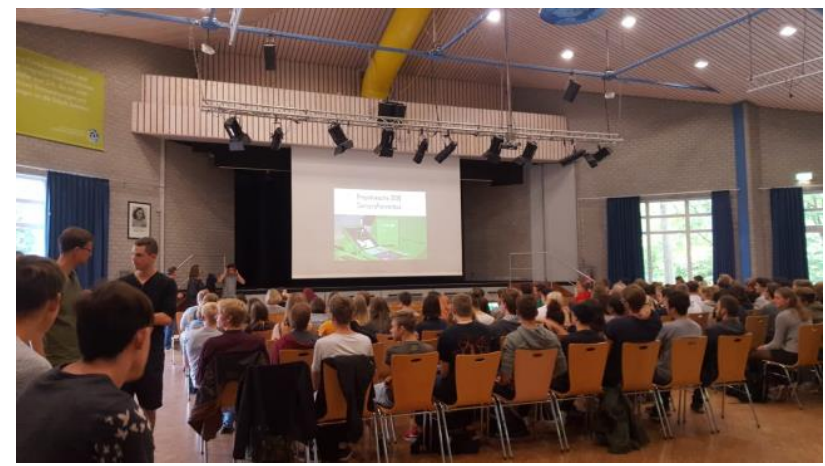

Figure 3: Presentation about the workshop week's progress to the mass

\section{RESULT AND DISCUSSION}

The students are taking care of the growth conditions and, are also controlling the artificial growth conditions with the watering plan created earlier. The lighting and irrigation conditions are being measured by the senseBox. The project will last for 8 weeks and still 6 more weeks are left to know the best suited conditions for the Salad plants. The suitable condition for growth of the plant will be determined based on 
the correlation between the measured values and the leaf sizes of the salad plants.

\subsection{Evaluation}

Since the project not only aims the best suitable condition of plant growth but also the knowledge sharing among different generations of students and to provide the school students with knowledge on sensors and GI, evaluations have been done based on the questionnaire surveys by participating the students in it to share their experiences throughout the workshop.

Though all the tasks were technically challenging, students found interesting to explore Arduino and senseBox with different sensors. Some students already familiar with Arduino found it easy to do the programming and to build data loggers for the sensors whereas it was new to most of the students but the students learnt and built the data loggers for the sensors in short time of interval. As per the questionnaire survey participated by the 24 students for the whole 5 project groups, $21.7 \%$ students participated in this project survey; highest number of the students, $29.2 \%$ of the students voted for the grade 1 and lowest, $12.5 \%$ voted for the grade 5 with no voting for grade 6 and rest of the votes are in between grade 1 to 4 on the scale of 1 to 6 for Excellent to not interesting. While exploring the questionnaire further, the main reasons for the less grade included the difficulties associated with programming. Except for the one student who found the duration long, other students were satisfied or wanted longer time for the workshop.

Regarding the evaluations on the supervisors, majority of the students (>60\%) agreed about the supervisors (MSc Students) being active, motivating and enthusiastic, whereas few (20\%) thought that the supervisors were not consistently active throughout the project. Also, 14 students showed their willingness to continue learning about the projects in future and 19 students were happy with their own performances.

Based on the attendance, all the students, except 1 absent on the first day participated the workshop actively and presented their works and findings obtained so far to the big mass of school students in order to share and motivate other students as well for their engagement in similar projects. Both the supervisors and the students found the project very successful in terms of knowledge exchange and learning by doing approach.

Though only $33 \%$ of the students participated in the voting, it is a self-assessment for the future works regarding the difficulty level of programming to be taught to students, time duration, tasks management and ways of being proactive for both the students and supervisors.

\section{CONCLUSION}

This project provides school students with the knowledge about applications of sensors in agriculture, particularly for monitoring plant growth by measuring climate factors, how to use senseBox by using Arduino programming and blockly, visualization of sensors data in open sensemap. Besides, such projects provide Msc students, the ideas of sharing knowledge with school students and school students, the ideas about recent research happening in the field of STEM and GI fields thereby bridging the transgenerational gap in knowledge sharing and cocreation. It further creates awareness among students on how can they contribute to the global Earth Observation program like Copernicus through local data measurement as citizen observatory projects and develops the interests among the students to pursue their future career in these fields.

\section{ACKNOWLEDGEMENTS}

The authors are thankful to GI@School Lab at IFGI, University of Muenster for its full support to carry out the project and Anne-Frank-Gesamtschule located in Havixbeck, Germany for providing the students and location for the workshop.

\section{REFERENCES}

Copernicus In Situ Component (no date). Available at: https://insitu.copernicus.eu/ (Accessed: 11 August 2018).

senseBox (no date). Available at: https://blockly.sensebox.de/ardublockly/?lang=de\&board=sense Box-mcu (Accessed: 5 October 2018).

[1] senseBox | The box with meaning (no date). Available at: https://sensebox.de/de/background (Accessed: 4 October 2018).

Soil Moisture Sensor Hookup Guide - learn.sparkfun.com (no date). Available at: https://learn.sparkfun.com/tutorials/soilmoisture-sensor-hookup-

guide?_ga $=2.26402238 .260308524 .1531141621$ -

27694235.1512467036 (Accessed: 4 October 2018).

Wirwahn, J. A. and Bartoschek, T., 2015 Usability Engineering For Successful Open Citizen Science. Free and Open Source Software for Geospatial (FOSS4G) Conference Proceedings: Vol. $15, \quad$ Article 54. DOI: https://doi.org/10.7275/R54J0C9W 